\title{
Francisco Raúl Carnese (1941-2019)
}

\author{
(4) María Fernanda Torres ${ }^{1,2}$ y Sergio Avena ${ }^{1,2,3}$ \\ ${ }^{1}$ Sección de Antropología Biológica, Instituto de Ciencias Antropológicas, Facultad de Filosofía y Letras, \\ Universidad de Buenos Aires (UBA) \\ ${ }^{2}$ Consejo Nacional de Investigaciones Científicas y Técnicas (CONICET) \\ 'Laboratorio de Antropología Biológica UBA - CEBBAD, Universidad Maimónides
}

Francisco Raúl Carnese había nacido el 15 de enero de 1941 en la ciudad de Avellaneda, al sur del Gran Buenos Aires, en un barrio de casas bajas habitadas por familias de clase media, trabajadores en su mayoría en la actividad industrial local y pujante por aquellos tiempos. Creció teniendo una infancia feliz. Esa ciudad marcó su vida por siempre, por su cercanía le posibilitó formarse en la escuela Joaquín V. González de Barracas como Perito Mercantil -una opción de salida laboral para ese entonces- y el club Atlético Independiente, en el corazón de su ciudad y en el suyo propio, le brindó el acceso a una nutrida biblioteca, que utilizó durante toda su trayectoria estudiantil, y por sobre todas las cosas mantener su pasión por el fútbol, particularmente por Independiente, según lo establecido en su "herencia por línea paterna".

Si bien su ocupación profesional no se inclinó por la formación que le habían otorgado sus estudios secundarios, cabe destacar que durante los mismos tuvo docentes que le despertaron nuevos intereses que lo conducirían a decidir su carrera universitaria. Un profesor de Merceología le brindó de manera apasionada conocimientos sobre la explotación del petróleo y de la Geología y despertó su interés por esta rama de la ciencia, inscribiéndose en 1960 en la carrera de Geología en la Facultad de Ciencias Naturales y Museo (FCNyM), de la Universidad Nacional de La Plata (UNLP) y mudándose a La Plata luego. Durante el primer año, cursó Fundamentos de Antropología una materia del ciclo común del Plan de Estudios 1958 para todas las licenciaturas de esa unidad académica y que lo llevó a cambiarse de carrera, para obtener el título de Licenciado en Antropología en el año 1966.

Durante su época de estudiante universitario, ya residiendo en La Plata, Raúl estuvo a punto de abandonar la carrera puesto que los contenidos que se desarrollaban no concitaban mayor atractivo. Para este momento, él rescataba la importancia que tuvo la Editorial Universitaria de Buenos Aires (Eudeba) creada en 1958 y dirigida por Boris Spivacow, quien en ocho años tradujo y publicó más de 800 títulos (Carnese, 2017) y la posibilidad de acceder a obras de autores como Wilfrid Le Gros Clark o Camille Arambourg sobre paleontología

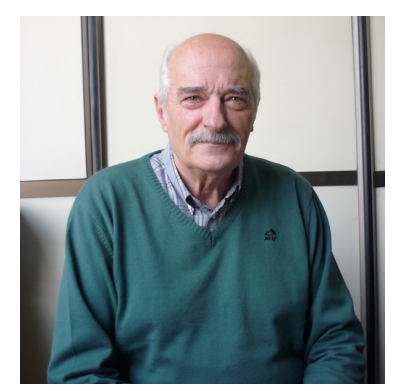

Fig. 1. Francisco Raúl Carnese

Nota de los editores:

Francisco Raúl Carnese, Raúl, fue miembro del Comité Editorial de RUNA entre los años 1989 y 2009 , 20 años trabajando en la difusión de la producción antropológica, impulsando la revista en tiempos en que no existían tecnologías como las actuales. Su partida ha sido una gran perdida para el Instituto y para quienes compartíamos cotidianamente ese espacio. También lo ha sido para RUNA, a la que aportaba su experiencia y sugerencias para mejorarla aún no siendo más parte de ella. Nos hacemos participes de esta nota, a manera de homenaje, quienes hemos compartido momentos de su vida y de su trabajo en el Instituto de Ciencias Antropoñogicas. 
y evolución humana, no incluidos en los programas de estudio, y cuya lectura mantuvieron su interés por la disciplina. A ese estímulo para continuar y concluir la licenciatura, Raúl rescataba también la visión esperanzadora que le brindó, su relación con el profesor Alberto Rex González, una concepción antropológica novedosa y muchas inquietudes. Así, junto a Rex González y un reducido número de estudiantes, entre los que se destacan Alejandro Isla y Héctor Mario Pucciarelli, trabajaron en la elaboración de un nuevo plan de estudios. La carrera de Antropología en ese momento, no tenía masa crítica de profesores en la orientación biológica, los contenidos teóricos que dictaban comulgaban mayoritariamente con la Escuela Histórico Cultural, caracterizada por un enfoque tipológico de la humanidad e inspiradora de ideas racistas. Esta propuesta de plan que para su concepción tuvo por eje central el reconocimiento de la diversidad de la especie humana como parte de su historia evolutiva, no estática sino dinámica, y la unidad de las ciencias antropológicas fue aprobada. Cabe destacar que también a través de Rex González contacta a Marcos Palatnik un Doctor en Química de la Facultad de Farmacia y Bioquímica (hoy de Ciencias Exactas, UNLP ) quien aceptó ser su director de tesis doctoral en una temática antropológica. Aplicando metodología innovadora, la serología genética, en tejidos momificados pudo realizar aportes para la comprensión de la distribución de tipos sanguíneos en grupos amerindios y del proceso de poblamiento americano, obteniendo en 1971 su título de Doctor en Ciencias Naturales (FCNyM, UNLP). Aquí cabe señalar que su formación en investigación científica la realizó como becario de la UNLP (1967-1969) y del Consejo Nacional de Investigaciones Científicas y Técnicas (CONICET) (1969-1973).

Raúl, tuvo una destacada participación en el gobierno universitario. En 1962 fue elegido delegado estudiantil ante el Honorable Consejo Académico de la Facultad de Ciencias Naturales y Museo (UNLP), y fue un activo militante en el centro estudiantil, lugar que lo comprometía responsablemente a ser un estudiante con muy buen desempeño, un referente para sus pares. Como lo expresara él mismo en el libro homenaje a Pucciarelli su compañero y amigo fraterno, "esa década se caracterizó por poseer un alto voltaje político que atravesó a todas las instituciones, incluida a las universidades" (Carnese, 2017). Creía, como sus compañeros de militancia, que la universidad no podía desentenderse de la sociedad y sus problemáticas. Ya graduado, impulsó el Proyecto Nueva Universidad (1973), cuyo objetivo era conectar la educación superior con la realidad social. Comprometido con ese proyecto asumió como Secretario de Asuntos Académicos y luego como Decano de la FCNyM, cargo que ocupó desde junio de 1973 a octubre de 1974 cuando la UNLP fue intervenida por parte del Poder Ejecutivo Nacional y Raúl cesanteado, como muchos otros docentes.

Su desempeño como docente lo inició siendo Ayudante alumno en la cátedra Fundamentos de Antropología (FCNyM) en 1964, luego Ayudante diplomado en la misma cátedra a partir de 1967 y en ese también año se incorporó primero como colaborador y luego, como Ayudante diplomado en el dictado en la cátedra de Biología general (Facultad de Farmacia y Bioquímica, UNLP) y en la misma unidad académica fue Jefe de Trabajos Prácticos en la cátedra Fisiología y Anatomía y Fisiología Patológica, de la unidad Genética Serológica, integrante del área Biología (1972-1973). En 1975 fue Profesor Adjunto de Biología General en la Universidad Nacional de Luján, pero al producirse el golpe de estado del 24 de marzo de 1976 es nuevamente despedido según la Ley de Seguridad Nacional, alejándose de la docencia por casi una década (Bonomo y Prates, 2019). 
Durante los años oscuros de la dictadura, gran parte de la población y en particular su generación, atraviesa momentos signados por el avasallamiento violento de los derechos humanos, muchos de sus compañeros son desaparecidos, otros deciden exiliarse fuera del país. Él y su familia -estaba casado con Alicia Caratini y tenían dos hijos pequeños, Francisco y Ana- deciden como estrategia de supervivencia dejar La Plata e instalarse en Buenos Aires. Inicialmente ambos sin trabajo, Raúl consigue ocuparse en la venta de casas prefabricadas y luego logra incorporarse como citogenetista -algo para lo cual no estaba capacitado y tuvo que formase- en la Fundación de Genética Humana entre los años 1976-1980, gracias a un ex-alumno de la Universidad de Luján, cuyo padre trabajaba allí. Un año más tarde, en 1981, ocupó la Jefatura en el Laboratorio de esa especialidad en el Hospital Italiano de Buenos Aires.

Con el retorno a la democracia durante el gobierno de Alfonsín se reestablecen cargos a cesanteados durante la dictadura militar y regresan al país muchos investigadores exiliados. En este contexto, Rex González fue nombrado en 1984 Director del Museo Etnográfico de la Facultad de Filosofía y Letras de la Universidad de Buenos Aires (FFyL, UBA). Raúl va a saludarlo y Rex le comenta que se abriría el concurso para cubrir un cargo de profesor en la materia Antropología Biológica de la Licenciatura en Ciencias Antropológicas (FFyL, UBA). Raúl sorprendido le dice que no es posible puesto que hacía casi 10 años que estaba alejado del ámbito académico. Sin embargo, ante su insistente estímulo -una vez más en su trayectoria- se inscribe, concursa y gana en 1986 el cargo de Profesor Adjunto y posteriormente, en 1989, el de Profesor Titular de la misma cátedra. Hacerse cargo de la asignatura concursada significó un gran desafío para él, los contenidos desarrollados hasta el momento se centraban en un marco histórico-cultural en el que básicamente se enseñaban aspectos morfoscópicos, descriptivos, muy alejados de la propuesta por él elevada, y hacían que los estudiantes tuvieran muy poco interés en la materia. Su programa para el dictado de las clases teóricas y prácticas rompió por completo con la tipología, ubicando a la Antropología Biológica en un campo disciplinario en la intersección de las Ciencias Biológicas y Sociales e incluyendo temas como microevolución, crecimiento y desarrollo, sociobiología, proceso de hominización, bioarqueología y análisis crítico de las clasificaciones raciales a la luz de los aportes de la genética de poblaciones, algo que en cierta manera despertó el interés de los estudiantes de la carrera en FFyL haciendo que muchos quisieran desempeñarse en la investigación de esta orientación antropológica.

Cabe señalar además que en este momento Raúl Carnese ingresa al programa denominado "Sistema de Apoyo para Investigadores Universitarios (SAPIU) creado por el CONICET, cuyo objetivo era otorgar un incentivo económico a la actividad de los docentes con dedicación exclusiva en las universidades nacionales o investigadores, que hubiesen padecido las desavenencias de los años de proscripción durante la dictadura. Este estímulo lo llevó a iniciar investigaciones en dos líneas, una de ellas daría continuidad a su trabajo en genética de poblaciones, esta vez orientado al conocimiento de las poblaciones aborígenes de Patagonia, indagándose también aspectos tales como demografía genética e histórica o medicina clínica; en tanto que la segunda línea de investigación se centró en el diagnóstico nutricional de la población involucrada que resultó en la elaboración de un estándar de crecimiento de la población infanto-juvenil mapuche de Río Negro, publicado por la imprenta de la FFyL (UBA) y que resultó de gran utilidad para los pediatras de esa región. Ambas líneas de investigación se caracterizaron por el trabajo interdisciplinario y el procedimiento mediante normas éticas de respeto a la comunidad involucrada. 
Sus primeras becarias fueron Marta Retyk (1988- 1992) y Alicia Susana Goicoechea (1988-1994), y bajo su dirección desarrollaron tesis doctorales sobre polimorfismos cromosómicos en una población toba de Villa Iapi (Quilmes) y polimorfismos grupales sanguíneos del sistema $\mathrm{ABO}$ en una población mapuche de Blancura Centro, provincia de Río Negro, Argentina, respectivamente.

En el año 1990 fue designado Director de la Sección de Antropología Biológica del Instituto de Ciencias Antropológicas (ICA, FFyL, UBA) y continúa desarrollando varias líneas de investigación, como los estudios antropogenéticos en comunidades de pueblos originarios y de poblaciones cosmopolitas y dando espacio -bajo su dirección- para la formación y perfeccionamiento de numerosos recursos humanos como becarios, tesistas y/o investigadores.

En lo referente a los estudios en poblaciones originarias, en el año 2003 firma un convenio ECOS-Sud (ANPCyT) con la Universidad de Toulouse (Francia) para el estudio paleogenético de individuos de grupos prehispánicos del territorio argentino. Lo que da la posibilidad de montar un laboratorio pionero en el país específicamente dedicado a desarrollar localmente estudios de ADN antiguo e iniciar una nueva línea de investigación a cargo de Cristina Beatriz Dejean. En lo referente a la comprensión de la composición de la población cosmopolita de varias ciudades de Argentina, él y su equipo, en la actualidad bajo la dirección de Sergio Avena, determinan en el acervo génico y a nivel individual, los aportes de los pueblos originarios y africanos, dando un argumento valioso para debilitar las narrativas dominantes de nuestro país, que los argentinos tenemos un origen europeo. Dirigió más de 20 proyectos de investigación financiados por organismos de ciencia y tecnología del país o extranjeros, publicando sus resultados en más de un centenar de reuniones científicas y revistas de la especialidad de prestigio nacional o internacional.

Paralelamente a esta tarea, también tuvo un rol importante para el desarrollo de la Antropología Biológica en cuanto a la creación de organizaciones que nuclearan a quienes transitaran en esa especialidad antropológica. Fue Miembro Fundador de la Asociación de Antropología Biológica Argentina (AABA), de la Sociedad Argentina de Genética y de la Asociación Latinoamericana de Antropología Biológica en la que fue electo dos veces Presidente (19961998 y 2006-2008). También es relevante la creación de la Revista Argentina de Antropología Biológica, órgano oficial de difusión de la AABA junto a Pucciarelli, tal como fuera mencionado su gran amigo y colega. Ambos trabajaron esforzadamente como Editores Jefes para que la revista se convirtiera en un ámbito de referencia para la especialidad en Argentina y Latinoamérica y lograra un reconocido prestigio (1996-2013). También formó parte de otros comités editoriales tales como los de la revista RUNA (ICA, FFyL, UBA), la Revista Internacional de Biología de Poblaciones (Órgano de la Sociedad Latinoamericana de Antropología Biológica) y la Revista Mexicana de Antropología Física (Instituto de Investigaciones Antropológicas de la Universidad Nacional Autónoma de México).

En la FFyL (UBA), además de su vuelta a la docencia en los cargos mencionados, también fue designado como Profesor Regular Titular Plenario (20052007), Profesor Consulto Titular (desde 2007) y Jefe de la Escuela de Posgrado (2012-2016). Asimismo, en esta unidad académica retomó su compromiso con cargos de gestión, fue Consejero Directivo por el Claustro de Profesores (19901994), Decano (1998-2001), Director de la Sección de Antropología Biológica (ICA) (desde 1990), Director del Departamento de Ciencias Antropológicas (1997) y Director alterno del ICA (2013-2017), entre otros. 
Raúl falleció el 14 de Junio de 2019. Para concluir este apretado detalle de su trayectoria que ilustra una vida de compromiso docente, científico y político, en defensa de un país mejor; cabe destacar su faceta en el trato cotidiano, para los que tuvimos la oportunidad de ser sus discípulos o colaboradores en la docencia pues podemos rescatarlo como alguien vehemente, responsable, amable, meticuloso, confidente y protector. Su pasión por lo que hacía resulta un ejemplo de ello, sin ninguna obligación siguió yendo a trabajar a la facultad hasta el último día que pudo hacerlo, participando de reuniones del ICA y esperando que saliera a la luz su libro "El mestizaje en la Argentina" el cual ahora ante su ausencia física, adquiere mayor relieve y representa una parte del invalorable legado, de su tránsito por la Antropología Biológica y nuestras vidas. Gracias Raúl, gracias Maestro, te vamos a extrañar!

\section{Fuentes consultadas}

» Albornoz M y Gordon A. (2011). La política de ciencia y tecnología en Argentina desde la recuperación de la democracia (1983-2009). En: M. Albornoz y J. Sebastián (Eds.). Trayectorias de las políticas científicas y universitarias de Argentina y España, CSIC, Madrid. Pp 1-46

» Bonomo M. y Prates L. 2019. Historias y voces de la Arqueología en el Museo de La Plata. Sociedad Argentina de Antropología (ms).

"Carnese F.R. (2017). Héctor Mario Pucciarelli. Su vida de estudiante. En: De Cómo Cruzar Fronteras en la Ciencia. Homenaje a Héctor M. Pucciarelli. Compilado por C. Paschetta; R. González-José; J.L. Lanata. Puerto Madryn y San Carlos de Bariloche: Instituto Patagónico de Ciencias Sociales y Humanas e Instituto de Investigaciones en Diversidad Cultural y Procesos de Cambio. Pp: 5-14.

» Gesteira S., Torres Agüero S., Hirsch M. (2017). Ciclo de Encuentros “Trayectorias”: Entrevista a Francisco Raúl Carnese. PUBLICAR. En Antropología y Ciencias Sociales, Año XV, NXXII: 93-110.

» Ottenheimer A.C. (2008). La creación de la licenciatura en Antropología en La Plata: un aporte a la historia de la enseñanza de la disciplina. IX Congreso Argentino de Antropología Social. Facultad de Humanidades y Ciencias Sociales - Universidad Nacional de Misiones, Posadas. 
